\title{
Research on the Value of the Modern Multimedia Technology in the Teaching of Medical Humanities Course
}

\author{
Kena Wang and Guohong Wang* \\ Qiqihar Medical University, Medical humanities teaching and research section (Qiqihar, \\ Heilongjiang, China, postal code161006) \\ *The corresponding author: wgh20052007@126.com
}

\section{Keywords: Modern Multimedia Technology; Medical Humanities Course; Value}

\begin{abstract}
The multimedia technology as one kind of modern teaching means is led into the theory class teaching in the colleges and universities widely, with rapid development modern computer technology and artificial intelligence technology. Medical Humanities course is an important part of curriculum in higher medical colleges and universities, it plays an irreplaceable and important significance and function to cultivate medical students' occupation spirit, occupation ethics and occupation emotion. The proper use of multimedia technology in the teaching process of Medical Humanities course, it not only stimulated Medical students' study interest in learning, arouse the enthusiasm of them participating in class, but also had broken that kind of tedious classroom teaching order in the past, and caused the classroom instruction to glow the new vitality and the vigor.

Facing the coming of the information age and the rapid development of modern science and technology, the traditional teaching mode is becoming obsolete, lack of new vigor and vitality; it has been unable to meet the new requirements of information society on the development of classroom teaching. Along with the gradual popularization and application of modern computer technology and artificial intelligence technology and theirs equipments, modern multimedia technology as a modern teaching method has been widely applied to teaching practice among theoretical courses. Multimedia technology as a modern means of information dissemination, it refers to the text, graphics, and pictures, sound, animation, video and other media to be edited, stored, played and can be carried out comprehensive treatment of them at the same time. Multimedia technology as a modern teaching method from the beginning of the application, which conquered the majority of educators with the characteristics of the image, vivid, novelty and flexibility, and it has been widely accepted and applied in classroom teaching. Today, the multimedia technology as a modern teaching means, the speed of its development, deep impact, and the popularity of the scope is unprecedented, its unique value in the process of teaching was also demonstrated and presented in practice.

Medical Humanities course as an important course in higher medical colleges and universities must be offered to cultivate medical students' occupation spirit, occupation morals, occupation emotion, through the medical humanistic spirit education to medical students, which makes students master medical and nursing professional skill, put the humanities concern spirit and emotion into their career at the same time, constructs the new bio-psycho-social medical model, with patient-centered, building harmonious relationship between doctors and patients, to serve patients, service to the society, cultivates comprehensive and qualified medical health personnel with noble occupation spirit, occupation ethics and occupation emotions.

At present, multimedia technology as a kind of modern teaching method has been widely used on the theory of teaching in colleges and universities around the world. It has also been widely introduced in the teaching of Medical Humanities course in higher medical colleges and universities, and increasingly plays its irreplaceable and important role in the teaching practice. Multimedia technology as a modern means of teaching has been widely accepted and adopted in the teaching process of Medical Humanities course, because of its own unique characteristics and its important
\end{abstract}


use value.

Specifically, modern multimedia technology has the following important role and practical value in the process of teaching of Medical Humanities course:

First, the application of modern multimedia technology, which can make the teaching contents of Medical Humanities course, become more images, vivid.

Medical Humanities course is a combination of knowledge of medicine and humanistic spirit, as a strong theoretical course, its' contents include two major fields: the medicine and the humanities, and contents involved widely and comparative boring, some of which is more difficult to understand. Thus in process of the teaching practice of this course, it has created a dilemma problem, namely the teachers are difficult to teach, and students are hard to understand. It is very difficult to achieve the expected purpose and effect of teaching. So how to make the teachers teach this course easily, and make students easily and willing to accept the teaching contents of the course, which has become an urgent practical problem need to be solved. While the introduction of modern multimedia technology, which just here acted as the "bridge" role to solve the puzzle. its' introduction made relatively obscure theory had become easy to understand. using this kind of teaching technology, through playing pictures and video files which relating to combination of medical professional and technical knowledge with the humanities spirit, makes the basic contents of teaching have the strong vitality and immediacy, it can give students create an immersive process to receive medical humanities education, provides intuitive feelings, let the students a better understanding of basic theoretical knowledge and contents of the Medical Humanities course, deepen the status and role of the medical humanistic spirit in their career. The introduction of modern multimedia technology both for the convenience of students to learn, but also to facilitate the teachers to teach, kill two birds with one stone; at the same time, the use of this modern multimedia technology is also further strengthen the relationship between teachers and students, making a more harmonious relationship between teachers and students, stimulate interest in the teachers' teaching and students' learning.

Second, the introduction of modern multimedia technology in the teaching process of Medical Humanities course, which was a great revolution in the teaching methods, and this kind of teaching method, showed its features of novelty and uniqueness it has in the teaching process.

The traditional Chinese teaching mode is that, "the blackboard with chalks, the teacher spoke on the stage, the students in the audience to hear", the boring teaching model was adopted in China for many years, and many people also gradually grew up in this traditional education mode. There is no denying that, the traditional teaching mode has its own unique advantages, and it has played an important and irreplaceable role in the social and historical background and environmental conditions at that time, even today in the 21 st century, the traditional teaching mode still exists, and there are still some people use it. But a series of new things have emerged such as bamboo shoots after a spring rain, with the development of science and technology, the progress of the society and the deepening of the reform, a series of new changes have taken place in people's social life, ideology and mental state. Reality tells us that, in the practice of modern teaching, the old teaching mode has been unable to meet the requirements of the development of teaching practice, and we must keep pace with the times, need to reform it and innovate it, to enrich it and develop it with something new, inject new vitality into it, these determines that we must improve the teaching methods, in accordance with the practical requirement in the new development of teaching. And multimedia technology as a modern teaching method was introduced into the field of classroom teaching in Medical Humanities course; this makes the Medical Humanities course to glow the new vitality and vigor. Modern multimedia teaching technology combines the traditional blackboard, slide, flip chart, video and sound and other media in one, comprehensive use of the advantages of various media, the picture and its' accompanying essay are both excellent, combination of dynamic and static, make variety of media closely cooperate with each other, form an organic unity of teaching methods. The application of this novel and unique teaching method greatly enhanced 
classroom teaching effect of Medical Humanities course, it not only attracted the attention of students, and fully mobilized the students' interest and enthusiasm and initiative in learning, but also enabled the students to concentrate their energies better on the classroom learning of Medical Humanities course, strengthened the comprehension of the problem intensively.

Third, the introduction of modern multimedia technology in the teaching process of Medical Humanities course, which can more effectively make full use of the limited teaching time in classroom, improved the efficiency of classroom teaching.

The traditional teaching mode mostly used blackboard-writing which of intuitive way to teach for students, but the Medical Humanities course as a strong theoretical course, in order to facilitate students ' learning and understanding, it needed to write a lot of blackboard-writing to explain in every class, if the teacher writes on the blackboard too slow in the classroom, or needs to write a lot of writing on the blackboard, or blackboard-writing is not clear enough, then there would be bound to a large part of time which originally very limited in classroom teaching was wasted in writing on the blackboard, the result was self-evident, these would seriously affect the efficiency of classroom teaching. But the introduction of modern multimedia technology in the teaching process, it is of great significance for improving the classroom teaching efficiency of Medical Humanities course. Before class, Teachers will be prepared in advance of blackboard-writing which needs to write in the classroom teaching process, stored in the self-made multi-media teaching courseware, using their own technology of multimedia courseware making who mastered; at the time of classroom teaching, the teachers shows blackboard-writing needed to write in the form of multimedia slides playing, in this way, a large number time of writing on the blackboard is saved, thus the teachers can teach more professional and theoretical knowledge to the students and answer their questions and doubts in the limited time in the classroom, fully and effectively use classroom teaching time, improve the efficiency and effect of classroom teaching.

Fourth, the introduction of modern multimedia technology in the teaching process of Medical Humanities course, which can better highlight the important problems and difficult problems in the process of teaching, good for students to accurately understand and master the important problems and difficult problems.

There are some important problems and incomprehensible problems in the teaching process of Medical Humanities course, how to make students better understand and grasp the important problems and difficult problems in the teaching process, it becomes an important task which needs to be solved before all the Medical Humanities course teachers. But the use of modern multimedia teaching technology, it has played an important role in solving the trouble, for the important problems and difficult problems in the teaching process of Medical Humanities course, when the majority of the teachers in the making of multimedia teaching courseware with modern multimedia teaching technology, they can carry out targeted teaching design according to the key issues and difficult problems, proceeding from reality, demonstrate the key issues and difficult problems in theory and in fact, selectively using the vivid and image of audio and video files, pictures, or factual material and slides, deepen students' knowledge and understanding about the problems. Thus through the using of multimedia teaching methods, it can not only highlight the key issues and difficult problems in the process of teaching, but also can strengthen students to understand and grasp of the key issues and difficult problems.

Fifth, the introduction of modern multimedia technology in the teaching process of Medical Humanities course, it is more beneficial to the teaching and learning of this course.

Teachers who teach the Medical Humanities course can use their mastery of the multimedia teaching technology and network knowledge, make full use of the advantages of modern developed Internet, build communication platform through the Internet, make teaching contents related to Medical Humanities course into a network version and put it on the Internet, and can also be in the school internal local area network (LAN) for students to learn and communicate according to the actual. Students can at any time study this course in their spare time, all problems will be easily 
solved as long as gently touch the mouse. At the same time the great development of instant communication tool, it also provides a convenient for the course learning, between students and teachers, students can take advantage of instant messaging tool for communication after the class, exchange knowledge, clarify views, guidance and answering questions, etc, and further consolidate knowledge of classroom learning. In addition, The multimedia teaching courseware which was made by teachers can be continuously modified and updated with the development of The Times and scientific theory, the emergence of modern multimedia technology and its own characteristics make this kind of revise and update more easy to operate, reduces the workload of teachers and improves teachers' work efficiency. The multimedia teaching courseware used by the teachers themselves in the classroom teaching can also be made into CD-ROM, so it is convenient to carry and spread the teaching content, and it can be used repeatedly, small volume and easy to save.

In the new stage of new century, modern multimedia technology as a kind of modern teaching means which is widely used in colleges and universities all over the world; it also plays an increasingly important and irreplaceable unique role in the teaching process of Medical Humanities course. This application of this technology in the teaching process of Medical Humanities course, it can be said to be a great reform in teaching methods, it is not only to reform the traditional teaching method and mode in the past, and to enrich and develop it, and makes the traditional teaching methods and the modern multimedia technology combined organically, showing the perfect combination of modern technology with traditional teaching methods in today with the rapid development of science and technology, gives the world a whole new experience, reflects the new era characteristics of advancing with The Times.

\section{Acknowledgement}

Fund project: the article is the research results which comes from the subject of the Chinese Medical Association, which named Research and practice on evaluation methods of medical students' humanities quality education in ideological and political course teaching. It is the sub project of Research on the mode of Humanistic Quality Education Guided by the spirit of professionalism in Applied Medicine Undergraduate College, Project number:2016B-RW036, Project leader: Cui guangcheng.

\section{References}

[1] Liu yan, Liu chao, Innovation thinking of multimedia teaching in Colleges and Universities [J], The public science and technology,2004,(8):57-58.

[2] Chang jinge, Using multimedia technology to improve the effect of classroom teaching[J], Teaching and management,2004,(36):46-47.

[3] Wang aihua, Design and application of multimedia courseware in the teaching of PLC [J], Vocational education research,2013,(7):169-170.

[4] Xue zheng, Thinking on optimization of multimedia in college English teaching[J], Education and Career, 2014,(29):140-141.

Author's brief introduction: Wang kena (1977.11-), female, instructor of Qiqihar Medical University Medical humanities teaching and research section ,Heilongjiang ,China .master of Renmin University of China, engaged in teaching and research of Medical Humanities course and Ideological and Moral Cultivation and Legal Basis course.

Author's brief introduction: Wang guohong (corresponding author ) (1977.12-), male, instructor of Qiqihar Medical University Medical humanities teaching and research section ,Heilongjiang ,China .master of Renmin University of China, engaged in teaching and research of Medical Humanities course and Medicine Ethics course. 